\title{
A Comparison of Students' Quantitative Reasoning Skills in STEM and Non-STEM Math Pathways
}

Emily Elrod

Florida Institute of Technology, eelrod2009@my.fit.edu

Joo Young Park

Florida Institute of Technology, jpark@fit.edu

Follow this and additional works at: https://digitalcommons.usf.edu/numeracy

Part of the Curriculum and Instruction Commons, Higher Education Commons, and the Science and Mathematics Education Commons

\section{Recommended Citation}

Elrod, Emily, and Joo Young Park. "A Comparison of Students' Quantitative Reasoning Skills in STEM and Non-STEM Math Pathways." Numeracy 13, Iss. 2 (2020): Article 3. DOI: https://doi.org/10.5038/ 1936-4660.13.2.1309 


\title{
A Comparison of Students' Quantitative Reasoning Skills in STEM and Non-STEM Math Pathways
}

\begin{abstract}
Quantitative Reasoning (QR) is essential for today's students, yet most higher education institutions have not effectively addressed this issue. This study investigates students' quantitative reasoning in STEM and Non-STEM math pathways using a non-proprietary, NSF grant-funded instrument, the Quantitative Literacy \& Reasoning Assessment (QLRA). Participants were students enrolled in at least one college-level math pathway course at a large public institution in the southeastern US. The results showed a significant difference between STEM and Non-STEM students' QLRA scores, with STEM students $(n=244, M=27 \%$, $S D=16.21 \%)$ scoring, on average, about $6 \%$ higher than Non-STEM students $(n=295, M=21.1 \%, S D$ $=11.38 \%$ ). STEM students who were further along in their math sequence, i.e. Pre-calculus/Trigonometry and Calculus I, had a higher QLRA score than those taking the gateway math courses in that pathway. Non-STEM students who took additional math courses also had a higher QLRA score than those in the entry-level math course. However, the students overall had relatively low QR skills $(n=539, M=23.78 \%$, $S D=14.07 \%$ ). These results highlight the need for an increased understanding of the math pathways initiative and its relationship with quantitative reasoning. Thoughtful and deliberate scrutiny of curriculum and pedagogy is important in all math pathways as it relates to the development of quantitative reasoning skills.
\end{abstract}

\section{Keywords}

quantitative reasoning, math pathways, STEM

\section{Creative Commons License}

(c) (i) (9)

This work is licensed under a Creative Commons Attribution-Noncommercial 4.0 License

\section{Cover Page Footnote}

Emily Elrod is a doctoral student in the Department of Mathematical Sciences at the Florida Institute of Technology.

Joo Young Park is Assistant Professor in the Department of Mathematical Sciences at Florida Institute of Technology. 


\section{Introduction}

The ability to interpret numerical information to make informed decisions is a necessity in today's world. "[Just] as the printing press gave the power of letters to the masses, so the computer gives the power of numbers to ordinary citizens" (Steen 1997, xv). Quantitative reasoning, sometimes referred to as quantitative literacy or numeracy, can be defined as "the habit of mind, competency, and comfort in working with numerical data" (Karaali et al. 2016, 32). Jesse Wilkins (2000) stated, "In the 21st century, the constitution of a person's functional literacy must extend beyond reading and writing to include an ability to cope with quantitative information" (405).

"Data, graphs, and statistics both enrich and confuse our lives. Numbers and quantities overwhelm current events, from medical reports to political trends, from financial advice to social policy. News is filled with charts and graphs, while quantitatively based decisions control education, health, and government" (Steen 1999, 8). Yet when presented with numerical information, many people lack the skills and confidence to handle these situations (Steen 1997; Steen 1999; Madison and Steen 2008).

\section{Quantitative Reasoning in Higher Education}

Relatively few colleges or universities have made quantitative literacy a major curricular focus. Of those that do, it is rare to find any whose expectations exceed what the National Council of Teachers of Mathematics now recommends for all high school graduates. Both the Mathematical Association of America and the American Mathematical Association of Two-Year Colleges have issued reports containing recommendations for quantitative literacy in undergraduate courses, but very few institutions have programs that meet these guidelines. In 2003, the National Assessment of Adult Literacy was administered to college students across the United States. The results showed that 20 percent of students at four-year institutions and 30 percent of students at two-year institutions function only at the most basic level of quantitative literacy (Madison and Steen 2008). Thus, concern about quantitative reasoning in education remains. However, there are some higher education institutions attempting to address this issue of students' developing quantitative reasoning skills.

Agustin et al. (2012) presented the results of a study conducted in conjunction with Southern Illinois University Edwardsville's (SIUE) journey of general education reform. In 2005, a review of the general education program revealed that it was possible for a student to graduate from SIUE without taking a quantitative course. Therefore, one critical component of the new general education program was the implementation of a quantitative reasoning requirement. This requirement is fulfilled by either completing the course QR 101: Quantitative Reasoning or by 
passing a proficiency examination within the first thirty semester hours. Since QR 101 was a new course at the time, much skepticism was expressed about its anticipated effectiveness and potential applicability. The most common issues raised included, "college students should be numerically literate and therefore do not need QR 101, QR 101 is a 'watered-down' math class and students will be disappointed and bored with its content, and students who are required to take math classes as part of their program should be exempt from taking QR 101" (Agustin et al. 2012, 307). Having had no prior course that addressed quantitative reasoning, it became necessary for SIUE to take an empirical approach to confront the issues that were raised. In particular, the claim that students whose degree programs require a significant math component (e.g., calculus) will acquire adequate quantitative reasoning skills as part of their chosen major needed to be examined.

The results of the study showed that taking one or more traditional math courses does not necessarily develop quantitative reasoning (Agustin et al. 2012). The study reported that, with a minimum of $70 \%$ considered passing, only $53.06 \%$ of Calculus 1 students passed the assessment, which was the highest pass rate of all courses tested, so about half of the students in the traditional math course sequence through Calculus were still falling short in the necessary skill of quantitative reasoning. According to Agustin et al. (2012), the study showed that taking one or more traditional math courses does not necessarily develop quantitative reasoning, suggesting that STEM majors may be well equipped to compute calculations relative to their field of study, but their ability to handle quantitative information in real-world experiences was still lacking. Furthermore, this study concluded that while a traditional math course tends to focus on computation in limited contexts, a quantitative reasoning math course concentrates on practical application and the ability to formulate quantitative arguments.

Another example of a Quantitative Literacy (QL) college program can be found at Colby-Sawyer College. Their QL mission statement is "students should have the "necessary skills to understand and use quantitative information in their personal and professional lives"' (Steele and Kilic-Bahi 2010, 2). To achieve this mission, entry-level math courses were converted to QL courses and a series of faculty-development workshops had been held to encourage faculty in all disciplines to include QL activities in their classes. After implementing their QL program, Colby-Sawyer examined its effectiveness. The results showed that seniors scored higher than freshman did in QL, indicating they had improved the quantitative reasoning skills over the course of their college career. However, the seniors on average were only able to solve less than $55 \%$ of the QL problems.

Steele and Kilic-Bahi (2010) suggest that an increase in quantitative skills assessment is necessary and the results of such assessments should be published to further guide this relatively new field of study. Additionally, they suggest more quantitative skills need to be included in the curriculum. 


\section{Math Pathways}

Traditionally, students were required to take algebra-laden courses to meet the mathematics curriculum requirement to obtain any undergraduate degree, regardless of degree major or career goals (Gaze et al. 2014). Within the last decade, there has been increased momentum toward "multiple pathways into and through mathematical sciences curricula, some of which should include early exposure to statistics, modeling, and computation" (Saxe et al. 2015, 13). This important work has been focused on providing various course sequences for students to fulfill math graduation requirements by taking courses with mathematical content that is applicable to specific degrees and careers.

As a result, many higher education institutions have begun encouraging NonSTEM students to take math courses in other branches of mathematics, such as statistics and liberal arts math, rather than traditional algebra courses. While the math pathway initiative is meant to include quantitative reasoning (Hoang et al. 2017), in a haste to adopt a math pathways model, some of the math courses being offered by post-secondary institutions are merely algebra alternatives and do not directly address deficiencies in quantitative literacy.

Moreover, for students majoring in the STEM fields, the math pathway requirements have typically remained unchanged. "Conventional wisdom dictates that calculus, in particular, holds pre-eminent status as the gateway to STEM. Fifty years ago, if you asked STEM faculty in universities and colleges for the mathematical pre-requisites for success in calculus, they undoubtedly would reply algebra, with a bit more algebra, some trig, and then more algebra" (Gaze 2014, 1). Still today, STEM students often take these traditional math courses to meet the prerequisites needed to eventually enter the Calculus sequence. "Not only does the GATC [Geometry, Algebra, Trigonometry, Calculus sequence] completely abandon the fundamental middle school math topics necessary for quantitative literacy but this superabundance of algebra taught in the abstract fosters math phobia and supports the culturally acceptable stance that math is not relevant to everyday life" (Gaze 2014, 1).

\section{Objectives and Research Questions}

Building upon the previous research of undergraduate students' QR skills assessment (Steele and Kilic-Bahi 2010; Gaze et al. 2014), the purpose of this study is to disaggregate assessment data by math pathway. This study looked at the STEM math pathway as compared to all other math pathways collectively, defined as the Non-STEM math pathway. This study also included additional analysis as to the relationship between the math course the student was currently enrolled in and their quantitative reasoning skills development. While previous research (Agustin et al. 2012) has indicated that traditional math courses are not necessarily sufficient for

STEM students to develop quantitative reasoning skills, this study examined both 
STEM and Non-STEM math pathway courses to better understand the relationship between those math courses and the development of QR skills. Furthermore, this study disaggregated the data by race and gender as well.

The guiding questions for this study are:

1. What is the relationship between students' QR skills and their math pathways, gender, and race?

2. What is the relationship between QR skills in STEM pathway students and their current math course, gender, and race?

3. What is the relationship between QR skills in Non-STEM pathway students and their current math course, gender, and race?

\section{Method}

A quantitative method was used in this study to investigate the relationship between quantitative reasoning skills and its associated factors. The population of interest is undergraduate students completing math pathway courses in accordance with their degree requirements, although due to constraints, the study was conducted at only one large, public, open access college in the central region of a southeastern state. The sample obtained was a convenience sample, and participation was voluntary.

\section{Participants}

The target population in this study is a set of students enrolled in at least one math class at one of the state colleges in one of the southeastern states. This open access institution is comprised of five separate campuses, but only one of the campuses participated in this study. College-wide enrollment is over 60,000 students with $36 \%$ of the population being full-time students and $64 \%$ of the population being part-time students. The median student age is 20 , and the race/ethnicity characteristics are: Caucasian 35.1\%, Hispanic 29.5\%, African American 17.0\%, Asian $4.8 \%$, Multi-Race $2.5 \%$, Other $0.7 \%$, and Unknown $10.5 \%$.

\section{Research Setting}

In the State College System, there are 28 public colleges that adhere to the Statewide Course Numbering System, which outlines the topics in each math course taught in the State College System. The participants in this study were enrolled in one of the college credit-bearing math courses offered by the selected institution. These courses include Intermediate Algebra, College Algebra, Precalculus Algebra/Trigonometry, Calculus 1, Statistics, and Liberal Arts Math. The math courses a student takes are dependent on their major and what prerequisites they have fulfilled. To support advising, the State College System created Meta-Major Pathways to guide associate degree-seeking students in their course selection to align with their intended academic and career goals. Figure 1 illustrates the math pathways depending on Meta-Major at the selected institution. 
For the STEM math pathway, the first math course a student would likely take is Intermediate Algebra, followed by College Algebra, then both Precalculus and Trigonometry, and Calculus 1 followed by the remainder of the Calculus sequence if needed for the specific degree major. For Non-STEM majors, the typical first math course would be Intermediate Algebra, followed by College Math, and then either Statistics or Liberal Arts Math depending on the degree major. Business majors have a math pathway that combines some math courses typically for STEM students and some math courses typically for Non-STEM students. Due to limitations beyond the researchers' control, the Business math pathway was not included in this study.

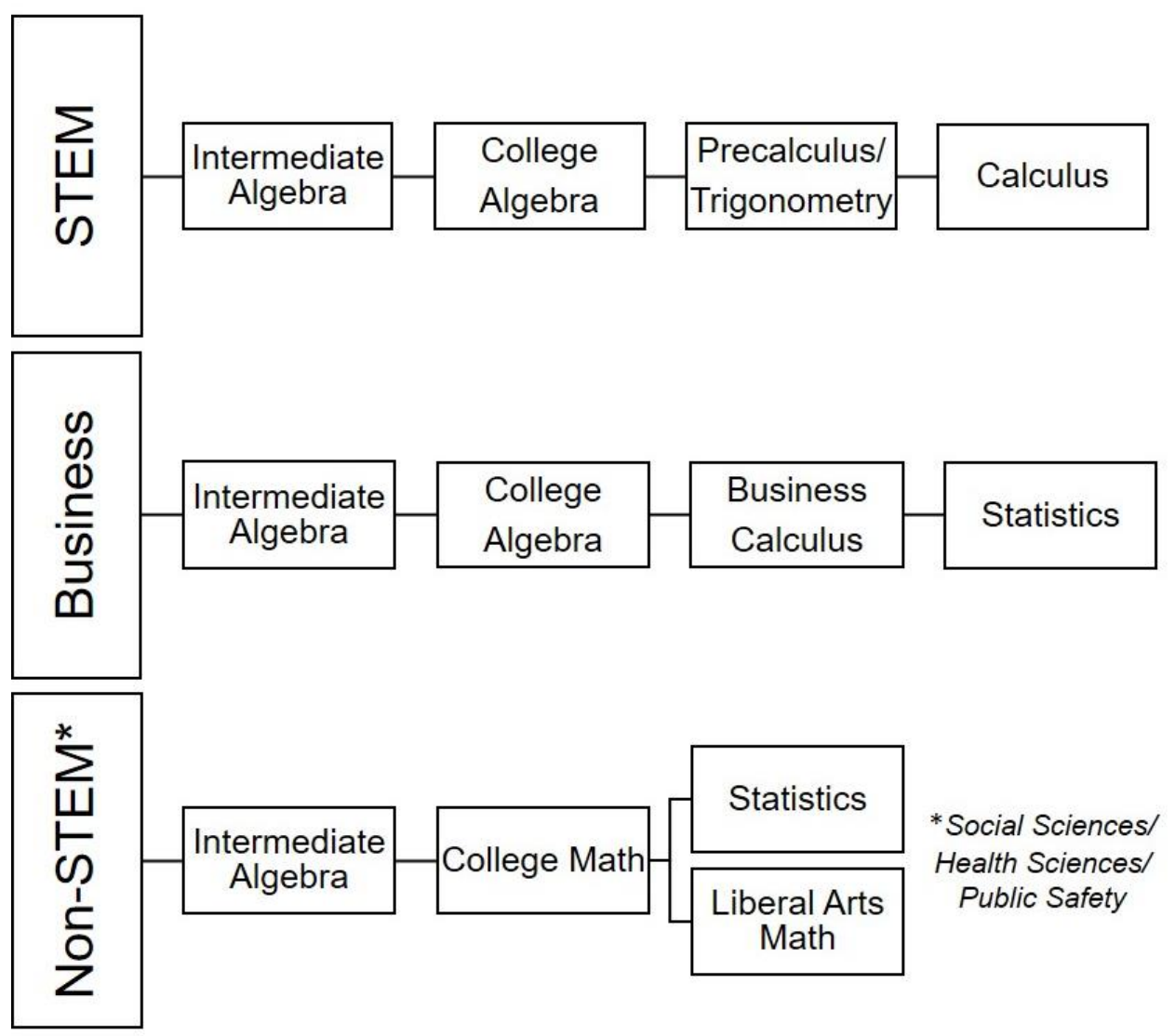

Figure 1. Math Pathways by Meta-Major

\section{Instrumentation}

This study was conducted with the use of the Quantitative Literacy \& Reasoning Assessment (QLRA), an instrument that is both valid and reliable. The content validity of this assessment is supported by its authors' QR field expert status, 
internal consistency, and related analyses at one institution demonstrating a high correlation to both math/science GPA and cumulative GPA (Gaze et al. 2014). "Overall reliability was tested using Cronbach's alpha, a statistic between 0 and 1 that increases as the inter-correlations of items increase. Thus, it is a measure of the internal consistency or reliability that all items are measuring the same underlying construct. For the 2012 administration, Cronbach's alpha was 0.866, and, in 2013, it was 0.862" (Gaze at al. 2014, 8).

An NSF-supported QLRA project team developed the instrument. After two iterations of constructing the assessment, its current form consists of 20 multiplechoice quantitative literacy/reasoning questions, 5 demographic questions, and 5 attitude survey questions. The 20 multiple-choice questions came from existing tests used at several of the project team colleges. The attitude survey questions were chosen from Dartmouth College's Math Attitudes Survey and the Subjective Numeracy Scale.

\section{Procedure}

After obtaining approval from the Institutional Review Board, math faculty members at the research site were recruited to administer the assessment through their courses. Those that agreed to administer the assessment were provided with a brief training video on how to administer the QLRA. This assessment was administered electronically using an online learning management system. This system is only accessible to current students and only allowed students enrolled in the course to access the materials of that class. This limitation provided test security since the assessment could not be accessed by the public. For faculty who chose to have their class participate, certain settings were incorporated to avoid academic dishonesty. These settings included the use of a Lockdown Browser, a 60-minute time restriction, and a force completion in one sitting, all designed to provide accurate results.

To encourage students to complete the assessment, faculty had the option of offering an incentive, such as extra credit. The assessment was only given once during the semester, specifically the last month of the semester, so most of the material included in a particular course had been covered. The assessment was made available to participants for a two-week period.

\section{Results}

Multiple Regression analysis was used to examine the relationship between students' QR skills and other variables - math pathways, gender, and race. There was a total of 539 viable test results with a mean score on the QLRA of $23.78 \%$. The descriptive statistics for the participants can be found in Table 1. 
Table 1

Descriptive Statistics for Students QRLA Score

\begin{tabular}{lllll}
\hline \hline & & $\boldsymbol{N}$ & Mean (\%) & Std. Dev. (\%) \\
\hline Math Pathway & STEM & 244 & 27 & 16.21 \\
& Non-STEM & 295 & 21.1 & 11.38 \\
& Female & 328 & 21.89 & 12.75 \\
& Male & 207 & 26.84 & 15.59 \\
& Unanswered & 4 & 20 & 7.07 \\
Race & White & 127 & 27.17 & 15.87 \\
& Hispanic/Latino & 285 & 23.19 & 13.62 \\
& Black & 62 & 18.95 & 9.8 \\
& Other & 62 & 24.6 & 14.61 \\
& Unanswered & 3 & 18.33 & 7.64 \\
Total & & & & \\
\hline \hline
\end{tabular}

Students in the STEM math pathway when completing this assessment on average scored $5.58 \%$ higher than those in the Non-STEM pathways $(t=4.74$, $p<0.05$ ). (See Table 2.) Students who identified as Female on average scored $4.09 \%$ lower than those who identified as Male $(t=-3.42, p<0.05)$. Previous research has indicated that gender is a significant factor in the chosen instrument of this study (Gaze et al. 2014). Some of the race variables were statistically significant with Hispanic/Latino $(t=-2.89, p<0.05)$ and Black $(t=-3.63, p<0.05)$. Students who identified as Hispanic/Latino on average scored $4.13 \%$ lower than students who identified as White, and students who identified as Black on average scored $7.57 \%$ lower than students who identified as White.

Table 2

Multiple Regression Coefficients for Students QLRA Score

\begin{tabular}{lcccc}
\hline \hline Term & $\begin{array}{c}\text { Unstandardized } \\
\text { Coefficient (\%) }\end{array}$ & $\boldsymbol{t}$-Ratio & Prob> $|\boldsymbol{t}|$ & $\begin{array}{c}\text { Standardize } \\
\text { Coefficient }\end{array}$ \\
\hline Constant & 27.18 & 18.23 & $0.0001^{*}$ & 0 \\
STEM & 5.58 & 4.74 & $0.0001^{*}$ & 19.76 \\
Female & -4.09 & -3.42 & $0.0007^{*}$ & -14.22 \\
Hispanic or Latino & -4.13 & -2.89 & $0.0040^{*}$ & -14.68 \\
Black & -7.57 & -3.63 & $0.0003^{*}$ & -17.17 \\
Other & -3.28 & -1.57 & 0.1163 & -7.45 \\
\hline \hline
\end{tabular}

* Indicates a statistically significant difference

Examination of the assessment results of both math pathways was conducted. Multiple Regression was conducted to examine the relationship between specific math courses and students' QLRA score in each math pathway controlling for gender and race.

\section{QLRA Score for Students in the STEM Math Pathway}

Of the total 536 participants, 242 identified as STEM students with a mean score on the QLRA of $26.67 \%$. The descriptive statistics for STEM students can be found in Table 3. 
Table 3

Descriptive Statistics for STEM Students QRLA Score

\begin{tabular}{lllll}
\hline \hline \multirow{3}{*}{ Gender } & & $\boldsymbol{N}$ & Mean (\%) & Std. Dev. (\%) \\
& Female & 135 & 24.56 & 15.09 \\
& Male & 106 & 29.53 & 16.31 \\
& Unanswered & 1 & 10 & - \\
& White & 50 & 32.1 & 18.02 \\
& Hispanic/Latino & 131 & 26.49 & 15.31 \\
& Black & 25 & 19.6 & 10.98 \\
& Other & 35 & 25.14 & 15.17 \\
& Unanswered & 1 & 10 & - \\
\multirow{5}{*}{ Course } & Intermediate Algebra & & & 11.5 \\
& College Algebra & 61 & 22.46 & 12.32 \\
& Precalculus/Trigonometry & 35 & 22.14 & 17.04 \\
& Calculus 1 & 35 & 27.71 & 18.72 \\
& Statistics & 69 & 34.78 & 12.4 \\
& College Math/Math for Liberal Arts & 19 & 27.89 & 10.53 \\
& & 23 & 17.83 & $\mathbf{1 5 . 8}$ \\
\hline \hline
\end{tabular}

STEM students enrolled in Precalculus/Trigonometry when completing this assessment on average scored $6.36 \%$ higher than those in Intermediate Algebra $(t=2.02, p<0.05)$, and STEM students enrolled in Calculus when completing this assessment on average scored $10.64 \%$ higher than those in Intermediate Algebra $(t=3.93, p<0.05)$. (See Table 4.) Some of the race variables were statistically significant with Hispanic/Latino $(t=-2.09, p<0.05)$, Black $(t=-2.93, p<0.05)$, and Other $(t=-2.13, p<0.05)$. Students who identified as Hispanic/Latino on average scored $5.2 \%$ lower than students who identified as White, students who identified as Black on average scored $10.91 \%$ lower than students who identified as White, and students who identified as Other on average scored $7.01 \%$ lower than students who identified as White.

Table 4

Multiple Regression Coefficients for STEM Students QLRA Score

\begin{tabular}{lcccc}
\hline \hline Term & $\begin{array}{c}\text { Unstandardized } \\
\text { Coefficient }(\%)\end{array}$ & $\boldsymbol{t}$-Ratio & Prob>|t| & $\begin{array}{c}\text { Standardize } \\
\text { Coefficient }\end{array}$ \\
\hline Constant & 29.35 & 9.39 & $0.0001^{*}$ & 0 \\
College Algebra & -1.59 & -0.49 & 0.6230 & -3.44 \\
Precalculus/Trigonometry & 6.36 & 2.02 & $0.0445^{*}$ & 14.11 \\
Calculus 1 & 10.64 & 3.93 & $0.0001^{*}$ & 29.64 \\
Statistics & 3.87 & 0.97 & 0.3339 & 6.41 \\
College Math/Math for Liberal Arts & -4.14 & -1.11 & 0.2661 & -7.49 \\
Female & -1.94 & -0.96 & 0.3356 & -5.97 \\
Hispanic or Latino & -5.20 & -2.09 & $0.0374^{*}$ & -16.03 \\
Black & -10.91 & -2.93 & $0.0037^{*}$ & -20.47 \\
Other & -7.01 & -2.13 & $0.0345^{*}$ & -15.21 \\
\hline \hline
\end{tabular}

* Indicates a statistically significant difference

\section{QLRA Score for Students in a Non-STEM Math Pathway}

Of the total 536 participants, 294 identified as Non-STEM students with a mean score of $21.1 \%$. The descriptive statistics for STEM students are in Table 5. 
Table 5

Descriptive Statistics for Non-STEM Students QLRA Score

\begin{tabular}{lllll}
\hline \hline \multirow{3}{*}{ Gender } & & $\boldsymbol{N}$ & Mean (\%) & Std. Dev. (\%) \\
& Female & 191 & 19.82 & 9.46 \\
& Male & 100 & 23.7 & 14.06 \\
\multirow{5}{*}{ Race } & Unanswered & 3 & 23.33 & 2.89 \\
& White & 74 & 23.11 & 11.16 \\
& Hispanic/Latino & 154 & 20.39 & 11.31 \\
& Black & 37 & 18.51 & 9.04 \\
& Other & 27 & 23.89 & 14.1 \\
& Unanswered & 2 & 22.5 & 3.54 \\
\multirow{5}{*}{ Course } & Intermediate Algebra & & 18.03 & 9.68 \\
& College Algebra & 66 & 24.06 & 14.15 \\
& Precalculus/Trigonometry & 79 & 16.43 & 6.9 \\
& Calculus 1 & 1 & 15 & - \\
& Statistics & 26 & 20 & 8.72 \\
& College Math/Math for Liberal Arts & 125 & 21.8 & 10.71 \\
& & $\mathbf{2 9 4}$ & $\mathbf{2 1 . 1}$ & $\mathbf{1 1 . 3}$ \\
\hline \hline
\end{tabular}

Non-STEM students enrolled in College Algebra when completing this assessment on average scored 7.12\% higher than those in Intermediate Algebra $(t=3.72, p<0.05)$, and Non-STEM students enrolled in Liberal Arts Math when completing this assessment on average scored $4.1 \%$ higher than those in Intermediate Algebra $(t=2.44, \mathrm{p}<0.05)$. (See Table 6.) Students who identified as Female on average scored $4.19 \%$ lower than those who identified as Male $(t=-3.09$, $p<0.05)$.

Table 6

Multiple Regression Coefficients for Non-STEM Students QLRA Score

\begin{tabular}{|c|c|c|c|c|}
\hline Term & $\begin{array}{l}\text { Unstandardized } \\
\text { Coefficient }(\%) \\
\end{array}$ & $t$-Ratio & Prob $>|t|$ & $\begin{array}{c}\text { Standardized } \\
\text { Coefficient }\end{array}$ \\
\hline Constant & 22.04 & 11.48 & $0.0001 *$ & 0 \\
\hline College Algebra & 7.12 & 3.72 & $0.0002 *$ & 26.69 \\
\hline Precalculus/Trigonometry & -0.37 & -0.08 & 0.9328 & -0.50 \\
\hline Calculus 1 & -0.19 & -0.02 & 0.9862 & -0.10 \\
\hline Statistics & 2.21 & 0.87 & 0.3848 & 5.56 \\
\hline College Math/Math for Liberal Arts & 4.10 & 2.44 & $0.0154 *$ & 17.93 \\
\hline Female & -4.19 & -3.09 & $0.0022 *$ & -17.69 \\
\hline Hispanic or Latino & -2.65 & -1.71 & 0.0888 & -11.69 \\
\hline Black & -3.87 & -1.75 & 0.0813 & -11.35 \\
\hline Other & 1.48 & 0.60 & 0.5494 & 3.78 \\
\hline
\end{tabular}

* Indicates a statistically significant difference

\section{Conclusion}

The results show that having any additional math course in both pathways appears to lead to a better QR score, but still relatively low quantitative reasoning skills regardless of which math pathway taken at this institution. The mean score for STEM students was $27 \%$, and although this is significantly higher than students in the Non-STEM pathway by about $6 \%$, these students on average are still only able 
to correctly answer about one-fourth of the QLRA questions. As indicated by both previous research (Steele and Kilic-Bahi 2010; Agustin et al. 2012) and the results of this study, there is still a great deal of improvement to be made in students' quantitative reasoning skills.

This study also highlights the need for an increased understanding of the math pathways initiative and its relationship with quantitative reasoning. The results of this study also support the importance of new curriculum development and pedagogical methods when developing math pathways. One such example is the Carnegie Foundation Quantway math pathway. This alternative to traditional developmental mathematics redesigned the content, pedagogy, and structure of traditional mathematics sequences, which has been shown to be an effective alternative to the traditional developmental mathematics sequence (Yamada et al. 2018). Additionally, this work is also being advanced through the Mathematics Pathways initiative at the Charles A. Dana Center at The University of Texas at Austin. ${ }^{1}$ Building on their alliance with Carnegie, the Dana Center Mathematics Pathways (DCMP) also seeks to revise course sequencing, content, and pedagogy in both developmental and college-level math courses with a developmental math course that emphasizes statistical and quantitative reasoning skills, as well as models for three alternative college-level math pathways - statistics; quantitative reasoning; and a path to calculus for STEM majors (Rutschow et al. 2017).

The results of this study also indicate that it is not just Non-STEM math pathways that need to address quantitative reasoning skills. Thoughtful and deliberate scrutiny to the curriculum and pedagogy for STEM math courses should be considered as well. As Gaze (2014) stated, "what is needed is a better way to teach algebra. A rigorous QR course can provide just the setting by grounding algebra in real-world context" (3). Additionally, creating quantitatively literate citizens does not preclude creating more scientists and engineers. "In some sense, they are two sides of the same coin. The QR community seeks to create a curriculum that addresses the quantitative reasoning needs of all students, providing meaningful engagement in mathematics that will simultaneously develop quantitative literacy and spark an interest in STEM fields" (Gaze 2014, 3).

It is important to note that poor performance on the assessment has no consequence. There was also no incentive to cheat, leaving the researchers to believe that the results would not be too different had the assessment counted for a grade (Steele and Kilic-Bahi 2010). Additionally, participation in this study was completely voluntary. The researchers recognize other math pathways, but the limitations of the sample collected only allowed for the examination of the STEM pathway as compared to all other math pathways collectively.

\footnotetext{
${ }^{1}$ To learn more about the Dana Center Mathematics Pathways, see https://www.utdanacenter.org/our-work/higher-education/dana-center-mathematics-pathways
} 
Additionally, readers should keep in mind the limitations of this study. While the curriculum for institutions within this college system are comparable, outside these institutions, the curriculum covered may vary greatly. Also, it is worth noting that the accessible population was only a single campus that has a high Hispanic population, which may vary from the institutional population parameters. Lastly, generalizations of these results should be made cautiously considering the convenience sampling.

For future research, it is suggested to have a measure of students' past math performance as part of the multiple regression analysis. Due to the constraints of this study, a reliable source of past math performance could not be collected, thus further exploration as to the impact of this variable should be examined. Additionally, the math pathway variable could be explored in more depth. Even though the data collected had more specific options than just STEM or Non-STEM, the sample sizes of particular degree majors were very small, thus it was not possible to analyze more specific pathways for Non-STEM majors. Furthermore, the degree major was self-reported data, so having a more reliable source for the pathway data could yield results worth examining as the students are not always aware of exactly how to classify their degree (e.g., Health Sciences majors would not be considered STEM degrees).

After having performed multiple regression on the data collected, it seems more in-depth analysis could provide a clearer picture in the explanation of these variables and their effects on quantitative reasoning. By performing different types of statistical analysis, such as path analysis, the study could provide a greater understanding of the effects of these variables, especially considering the course sequence for individual students can differ slightly, depending on where the student starts in their math pathway based on a possible placement test, whether a student chooses to take another math course as an elective, or switches majors, therefore changing math pathways midstream, and other such variations that could cause students to have different prerequisite knowledge or experiences than is typical for a particular course.

\section{References}

Agustin, M.Z., M. Agustin, P. Brunkow, and S. Thomas. 2012. "Developing

Quantitative Reasoning: Will Taking Traditional Math Courses Suffice? An

Empirical Study." The Journal of General Education, 61(4): 305-313. https://doi.org/10.1353/jge.2012.0037

Gaze, E.C. 2014. "Teaching Quantitative Reasoning: A Better Context for

Algebra." Numeracy, 7(1):1. https://doi.org/10.5038/1936-4660.7.1.1 
Gaze, E.C., A. Montgomery, S. Kilic-Bahi, D. Leoni, L. Misener, and C. Taylor. 2014. "Towards Developing a Quantitative Literacy/Reasoning Assessment Instrument.” Numeracy, 7(2):4. https://doi.org/10.5038/1936-4660.7.2.4

Hoang, H., M. Huang, B. Sulcer, and S. Yesilyurt. 2017. "Carnegie Math Pathways 2015-2016 Impact Report: A Five-Year Review." Carnegie Math Pathways Technical Report. Carnegie Foundation for the Advancement of Teaching.

Karaali, G., E.H. Villafane Hernandez, and J.A. Taylor. 2016. "What's in a Name? A Critical Review of Definitions of Quantitative Literacy, Numeracy, and Quantitative Reasoning." Numeracy, 9(1):2. https://doi.org/10.5038/1936-4660.9.1.2

Madison, B.L., and L.A. Steen. 2008. "Evolution of Numeracy and the National." Numeracy, 1(1):2. https://doi.org/10.5038/1936-4660.1.1.2

Rutschow, E.Z., J. Diamond, and E. Serna-Wallender. 2017. "Math in the Real World: Early Findings from a Study of the Dana Center Mathematics Pathways." Research Brief, Center for the Analysis of Postsecondary Readiness.

Saxe, K., L. Braddy, J. Bailer, R. Farinelli, T. Holm, V. Mesa, U. Treisman, and P. Turner. 2015. A Common Vision for Undergraduate Mathematical Sciences Programs in 2025. Washington DC: The Mathematical Association of America.

Steele, B., and S. Kilic-Bahi. 2010. "Quantitative Literacy: Does it Work? Evaluation of Student Outcomes at Colby-Sawyer College." Numeracy, 3(2):3. https://doi.org/10.5038/1936-4660.3.2.3

Steen, L.A. 1997. "Why Numbers Count: Quantitative Literacy for Tomorrow's America." New York: College Entrance Examination Board.

Steen, L.A. 1999. "Numeracy: The New Literacy for a Data-Drenched Society." Educational Leadership 57:8-13.

Wilkins, J.L.M. 2000. "Preparing for the 21st Century: The Status of Quantitative Literacy in the United States." School Science and Mathematics, 100(8):405418. https://doi.org/10.1111/j.1949-8594.2000.tb17329.x

Yamada, H., A.X. Bohannon, A. Grunow, and C.A. Thorn. 2018. "Assessing the Effectiveness of Quantway: A Multilevel Model with Propensity Score Matching." Community College Review, 258-287. https://doi.org/10.1177/0091552118771754 